\title{
CLINICAL ARTERIAL INFUSION OF CALCIUM GLUCONATE: THE PREFERRED METHOD FOR TREATING HYDROFLUORIC ACID BURNS OF DISTAL HUMAN LIMBS
}

\author{
ZHANG YUANHAI ${ }^{1}$, NI LIANGFANG ${ }^{1}$, WANG XINGANG ${ }^{2}$, JIANG RUIMING ${ }^{1}$, LIU LIPING ${ }^{1}$, \\ YE CHUNJIANG ${ }^{1}$, XIA WENHAO ${ }^{1}$, and HAN CHUNMAO ${ }^{2}$
}

${ }^{1}$ Zhejiang Quhua Hospital, Quzhou, China

Department of Burns

${ }^{2}$ 2nd Affiliated Hospital of Zhejiang University, College of Medicine, Hangzhou, China

Department of Burns \& Wound Care Center

\begin{abstract}
Objective: This study was designed to evaluate the efficiency and safety of arterial infusions of calcium gluconate to treat hydrofluoric (HF) acid burns of the distal human limbs. Materials and Methods: Eligible patients with HF burn limbs, collected from January 2008 to October 2011, were given the arterial infusion of calcium gluconate into the injured limbs. The measures of pain were conducted before the infusion, immediately after the infusion, $4 \mathrm{~h}$ after the infusion, and 2 days after the infusion by the visual analogy score (VAS). If the VAS score was higher than 4.0 at the time point $4 \mathrm{~h}$ after the first infusion, the infusion was repeated. The time of wound healing, and the number and ratio of the cases receiving the surgical operation were also evaluated. Results: A total of 118 patients, male (107 cases) and female (11 cases), were collected, including 64 cases of outpatients and 54 cases of inpatients. The age of the subjects ranged from 16 to 60 years, with the mean age of 37.6. The burn sites were located in the lateral limbs ( 28 cases) and in the unilateral limbs ( 90 cases). For 107 cases, the pain scores decreased quickly after the first infusion. The other 11 cases, with the VAS score higher than 4.0 at the time point $4 \mathrm{~h}$ after the first infusion, received the second infusion. The average time of wound healing and the ratio of the cases receiving the surgical operation were closely related to the interval from the injury to the reception of infusion. Conclusions: Arterial infusion of calcium gluconate, effectively relieving the pain, blocking wound progressive deepening, and causing no adverse effects, could be the preferential method to treat hydrofluoric acid burns of the distal human limbs.
\end{abstract}

Key words:

Hydrofluoric acid, Burn, Calcium gluconate, Arterial infusion

\section{INTRODUCTION}

Hydrofluoric acid (HF), a colorless poisonous corrosive liquid, has been widely used in the synthesis of organic fluorine compounds, semi-conductor production, glass etching, metal casting and in other industrial fields. During the production, transportation and usage of HF, this powerful inorganic acid easily causes burns individually or in batches, which usually occur on the distal limbs.

This work was financially supported by the Medical Health Platform Program of Zhejiang Province (2013ZD025), the Research Fund for the Doctoral Program of Higher Education (20130101120032) and the Natural Science Fund of Zhejiang, China (LQ12H15001).

Received: January 3, 2013. Accepted: December 12, 2013.

Corresponding author: W. Xingang, Department of Burns \& Wound Care Center, 2nd Affiliated Hospital of Zhejiang University, College of Medicine, Hangzhou, China (e-mail:wxg8157@163.com). 
The accidents of HF burns have occurred not only in the enterprises dealing with chemical production and transportation, but also in the daily life [1-3]. Among all the chemicals resulting in chemical burns, HF could become the first most common substance to cause chemical injuries [3].

Moreover, the fluoride ion can be absorbed quickly through the skin and further result in secondary lesions, such as serious skin necrosis, hypocalcemia, and severe pain [4]. To effectively treat the patients with HF exposure, immediate specific and specialized medical measures seem to be essential. In addition to the traditional measures for chemical injuries, arterial infusion of calcium gluconate has been reported as an effective method to treat chemical burns occurring due to $\mathrm{HF}[5,6]$. Herein, we report 118 cases of HF burns, who received intraarterial calcium gluconate treatment. We also emphasize the importance of the early management of the treatment and the efficacy and safety of this method used to treat HF burns of the distal human limbs systematically evaluated by observing the level of pain, the time and way of wound healing, and the occurrence of adverse reactions.

\section{MATERIALS AND METHODS}

\section{Clinical materials}

From January 2008 to October 2011, eligible patients with HF burns of distal lateral or unilateral limbs out of the inpatients and outpatients of the Department of Burns of Zhejiang Quhua Hospital or of the Department of Burns of 2nd Affiliated Hospital of Zhejiang University were enrolled in this retrospective study. The patients with inhalation injuries, disturbances of consciousness, severe diseases of important organs and other HF burns beyond the limbs were excluded. The teenage patients under the age of 14 were also excluded. The burn patients did not receive the same or similar treatment related to calcium gluconate after HF burns.
A total of 118 patients, male (107 cases) and female (11 cases), were collected, including 64 cases of outpatients and 54 cases of inpatients. The demographic and clinical characteristics of the 118 enrolled patients are listed in Table 1 . The age of the patients ranged from 16 to 60 years, with the mean age of 37.6. The burn sites were located in the lateral limbs (28 cases) and in the unilateral limbs (90 cases). The analysis of the data of the patients and the cause of the HF burns showed that except one case resulting from the accidental injury involving a glass detergent used in the kitchen, all the other cases were associated with the particular occupations of the subjects. 32 injuries occurred in the production plants, 39 during transportation, 11 during facility maintenance and repairs, 4 in the laboratory and the remaining 31 cases occurred in the glass sculpture, metal casting, electronics industries and so on. Among 107 patients with the burn wounds on the hands, there were 90 cases with finger burns and 17 cases with accompanying palm of the hand or back injuries.

Table 2 shows the distribution of 281 burned fingers of 107 patients. In the other 11 patients, their burn wounds mainly occurred on the sole of the foot, distal back and toes. Out of all 118 patients, only 34 cases $(28.8 \%)$ used protective equipment at the workplace and they were exposed to HF due to broken rubber gloves, shoes or clothes.

\section{Methods for arterial infusion of calcium gluconate}

In the patients injured immediately after the HF burn, their radial artery, dorsal pedal artery or posterior tibial artery of the injured site was selected as the puncture blood vessel. After successfull puncture along or against the blood flow, the mixed solution of $10 \mathrm{ml}$ of $10 \%$ calcium gluconate and $20 \mathrm{ml}$ of $10 \%$ glucose was injected slowly by the syringe pumps. The injection procedure finished in $15 \mathrm{~min}$, usually aroused the obvious burning sensation in the patients. 
Table 1. Demographic characteristics and clinical features of patients

\begin{tabular}{|c|c|c|}
\hline \multirow[t]{2}{*}{ Variable } & \multicolumn{2}{|c|}{$\begin{array}{l}\text { Patients } \\
(\mathrm{N}=118)\end{array}$} \\
\hline & $\mathrm{n}$ & $\%$ \\
\hline \multicolumn{3}{|l|}{ Gender } \\
\hline male & 107 & 90.7 \\
\hline female & 11 & 9.3 \\
\hline \multicolumn{3}{|l|}{ Age (years) } \\
\hline $16-30$ & 28 & 23.7 \\
\hline $31-40$ & 45 & 38.1 \\
\hline $41-50$ & 33 & 28.0 \\
\hline $51-60$ & 12 & 10.2 \\
\hline \multicolumn{3}{|l|}{ Burn sites } \\
\hline right hand & 50 & 42.4 \\
\hline left hand & 34 & 28.8 \\
\hline both hands & 23 & 19.5 \\
\hline one foot & 7 & 5.9 \\
\hline both feet & 4 & 3.4 \\
\hline \multicolumn{3}{|l|}{ Burn area (TBSA) $(\%)$} \\
\hline$<1$ & 105 & 89.0 \\
\hline $1-<2$ & 10 & 8.5 \\
\hline $2-3$ & 3 & 2.5 \\
\hline \multicolumn{3}{|c|}{ The time from injury to infusion (h) } \\
\hline$<12$ & 55 & 46.6 \\
\hline $12-<24$ & 32 & 27.1 \\
\hline $24-48$ & 18 & 15.3 \\
\hline$>48$ & 13 & 11.0 \\
\hline
\end{tabular}

TBSA - total body surface area.

Table 2. The distribution of 281 fingers of patients

\begin{tabular}{lcc}
\hline & \multicolumn{2}{c}{ Patients } \\
\cline { 2 - 3 } & Finger & \multicolumn{2}{c}{$(\mathrm{N}=107)$} \\
\hline Thumb & 77 & $\%$ \\
Forefinger & 86 & 27.4 \\
Middle finger & 67 & 23.6 \\
Ring finger & 31 & 11.0 \\
Little finger & 20 & 7.1 \\
\hline
\end{tabular}

\section{Wound treatment}

The wound treatment was conducted according to the following procedures. First, the bulla skin was removed and the affected fingernails or toenails were pulled out. If the nail was not destroyed completely, the injured part of the nail was cut off instead of removing the whole nail. Then, the wounds were washed with physiological saline, and soaked with wet gauze containing $10 \%$ calcium gluconate for $24 \mathrm{~h}$. All the wounds in this study were treated as follows: the wounds were cleaned by normal saline, disinfected with $1 \%$ cream of sulfadiazine silver, and covered with dressings changed every other day, until the wounds healed or were turned to surgical treatment.

\section{Evaluation}

Pain scoring

The measures of pain were conducted before the infusion, immediately after the infusion, $4 \mathrm{~h}$ after the infusion, and 2 days after the infusion by the visual analogy score (VAS) [7]. The VAS is usually a horizontal line, $100 \mathrm{~mm}$ in length, anchored by the extremes labeled "no pain" and "very severe pain". After providing written informed consent, patients were asked to mark on the line the point that they felt to represent their perception of their current state. The VAS score is determined by measuring in millimeters the fragment from the left hand end of the line to the point that the patient marks. If the VAS score was higher than 4.0 at the time point $4 \mathrm{~h}$ after the first infusion, the infusion and the pain evaluation were repeated.

\section{Wound healing}

For all the wounds, pictures were taken and the healing time was recorded. The number and ratio of the cases receiving the surgical operation were calculated. For all the cases, the time when the patients were injured, the time of the infusion, and the time of complete wound healing (defined as $>95 \%$ wound closure) were carefully recorded and analyzed. 


\section{Laboratory tests}

When the patients sought treatment for HF burns for the first time, the blood specimens were taken immediately to detect the concentration of calcium ion and magnesium ion. The urine specimens were also taken to obtain the values of the urine fluorides with the Ion-Selective Electrode method. For the patients after admission, the urine fluorides in the first morning urination were normally detected.

\section{Adverse effects}

During the arterial infusion of calcium gluconate, all the adverse effects, such as solution leakage, hematoma formation, vasculitis, tissue necrosis, and hypercalcemia were investigated and recorded.

\section{Statistical analysis}

All quantitative data were analyzed with SPSS 16.0 (USA). The measurement data were presented as the mean standard deviation, while the enumeration data were expressed by the constituent ratio. The comparisons of pain scores before and after the infusion were conducted with the Student's t-test. Statistical differences among the specimens were evaluated using a two-tailed Student's t-test. The value of $p<0.05$ was regarded as significant.

\section{RESULTS}

\section{Pain scoring}

107 cases, whose pain was obviously relieved after infusion, could go to sleep peacefully. Four h after the first infusion, 11 cases with the pain score higher than 4.0 received another infusion and the pain relief became obvious.

For 107 patients, the scores of pain before the infusion, immediately after the infusion, $4 \mathrm{~h}$ after the infusion and 2 days after the infusion were recorded as $6.32 \pm 1.67$, $2.80 \pm 0.90,2.69 \pm 0.77$, and 2.04 \pm 0.74 , respectively (Table 3). For the other 11 cases with the VAS score higher than 4.0 at the time point $4 \mathrm{~h}$ after the first infusion, the scores of pain before the infusion, immediately after the first infusion, $4 \mathrm{~h}$ after the first infusion, immediately after the second infusion, and 2 days after the first infusion were 7.68 \pm 1.18 , $4.72 \pm 0.89,4.45 \pm 0.47,3.09 \pm 0.51$ and $2.85 \pm 0.95$, respectively (Table 4). The pain scores after the infusion were significantly different than the scores before the infusion.

Table 3. The scoring of pain for 107 patients receiving one arterial infusion of calcium gluconate

\begin{tabular}{lcccc}
\hline \multirow{2}{*}{ Infusion } & \multicolumn{4}{c}{$\begin{array}{c}\text { Pain score } \\
(\mathrm{M} \pm \mathrm{SD})\end{array}$} \\
\cline { 2 - 5 } & before the infusion & immediately after the infusion & $4 \mathrm{~h}$ after the infusion & 2 days after the infusion \\
\hline Once & $6.32 \pm 1.67$ & $2.80 \pm 0.90^{*}$ & $2.69 \pm 0.77^{*}$ & $2.04 \pm 0.74^{*}$ \\
\hline
\end{tabular}

* Indicates a significant difference $(\mathrm{p}<0.05)$ compared to the pain score before the infusion.

Table 4. The scoring of pain for 11 patients receiving two arterial infusions of calcium gluconate

\begin{tabular}{lccccc}
\hline \multirow{2}{*}{ Infusion } & \multicolumn{5}{c}{$\begin{array}{c}\text { Pain score } \\
(\mathrm{M} \pm \mathrm{SD})\end{array}$} \\
\cline { 2 - 6 } & before the infusion & $\begin{array}{c}\text { immediately after } \\
\text { the first infusion }\end{array}$ & $\begin{array}{c}4 \mathrm{~h} \text { after the first } \\
\text { infusion }\end{array}$ & $\begin{array}{c}\text { immediately after } \\
\text { the second infusion }\end{array}$ & $\begin{array}{c}2 \text { days after the first } \\
\text { infusion }\end{array}$ \\
\hline Twice & $7.68 \pm 1.18$ & $4.72 \pm 0.89^{*}$ & $4.45 \pm 0.47^{*}$ & $3.09 \pm 0.51^{* \#}$ & $2.85 \pm 0.95^{* \#}$ \\
\hline
\end{tabular}

* Indicates a significant difference $(\mathrm{p}<0.05)$ compared to the pain score before the infusion.

\# Indicates a significant difference $(\mathrm{p}<0.05)$ compared to the pain score $4 \mathrm{~h}$ after the first infusion. 


\section{Wound healing}

In all 118 patients with HF burn wounds, significant healing results were obtained. In 103 cases, the wound healing process was finished by changing dressings, while 15 cases received the skin grafting or flap repair.

Among the patients receiving surgical treatments, 4 cases were treated by eschar excision and skin grafting; 4 cases received the excision of granulation tissue or necrotic phalanges and skin grafting; 7 cases were subjected to flap transplantation for the exposure of phalanges or tendons. In all the healed cases the abnormal appearance caused by the removal of nails was observed. 35 patients healed with a different degree of scar formation, out of whom 7 cases manifested a different degree of finger shortening deformation because of the terminal finger necrosis.

The time of wound healing was related to the first time when the patients sought treatment after experiencing HF burns. The later the arterial infusion began, the longer was the time of wound healing (Figure 1), and the higher was the ratio of the cases who needed to receive surgical treatment (Table 5). The average times of wound healing were $6.02 \pm 2.39,10.7 \pm 2.89,15.9 \pm 3.03$, and $24.8 \pm 2.48$ days, and the ratios of the cases receiving the surgical operation were $1.8 \%, 3.1 \%, 22.2 \%$, and $68.2 \%$ according to the infusion time within $12 \mathrm{~h}, 12-24 \mathrm{~h}, 24-48 \mathrm{~h}$, and beyond $48 \mathrm{~h}$ after experiencing the HF burns.

\section{Laboratory tests}

The values of serum calcium ion distributed from $1.88 \mathrm{mmol} / \mathrm{l}$ to $2.80 \mathrm{mmol} / \mathrm{l}$, and averaged as $2.29 \pm 0.17 \mathrm{mmol} / \mathrm{l}$ in all the cases, among which 5 cases revealed the values below

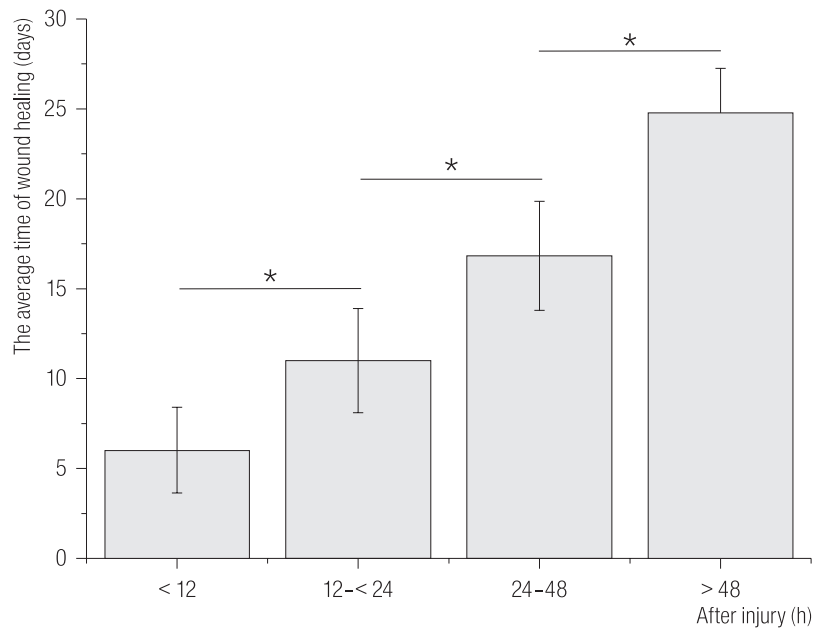

Fig. 1. The relationship between the infusion time and the average time of wound healing

the lower value of the normal level $(2 \mathrm{mmol} / \mathrm{l})$. The values of serum magnesium ion distributed from $0.54 \mathrm{mmol} / \mathrm{l}$ to $0.99 \mathrm{mmol} / \mathrm{l}$, and averaged as $0.83 \pm 0.09 \mathrm{mmol} / \mathrm{l}$ in all the cases, among which 3 cases revealed the values below the lower limit of the normal level $(0.66 \mathrm{mmol} / \mathrm{l})$. The average value of urine fluorides was $2.36 \pm 3.09 \mathrm{mg} / \mathrm{l}$, distributing from $0.14 \mathrm{mg} / \mathrm{l}$ to $25.8 \mathrm{mg} / \mathrm{l}$ in all the cases, and there were 62 cases with the values higher than the upper limit of $1.7 \mathrm{mg} / \mathrm{l}$. Figure 2 shows the changes in the morning urine fluorides of 14 admitted patients. The urine fluorides reached the peak on the 2nd day after their admission, then declined quickly, and returned to the normal level about 5 days after the admission.

\section{Adverse effects}

There were 4 cases of solution leakage among all the treated patients, which were recognized timely and treated by

Table 5. The ratio of cases operated on after the injury

\begin{tabular}{lcccc}
\hline \multirow{2}{*}{ Classification } & \multicolumn{4}{c}{ The infusion time since the injury } \\
\cline { 2 - 4 } & $<12 \mathrm{~h}$ & $12-<24 \mathrm{~h}$ & $24-<48$ & $>48 \mathrm{~h}$ \\
\hline Total cases (n) & 55.0 & 32.0 & 18.0 & 13.0 \\
Cases for operation (n) & 1.0 & 1.0 & 4.0 & 9.0 \\
Ratio (\%) & 1.8 & 3.1 & 22.2 & 68.2 \\
\hline
\end{tabular}




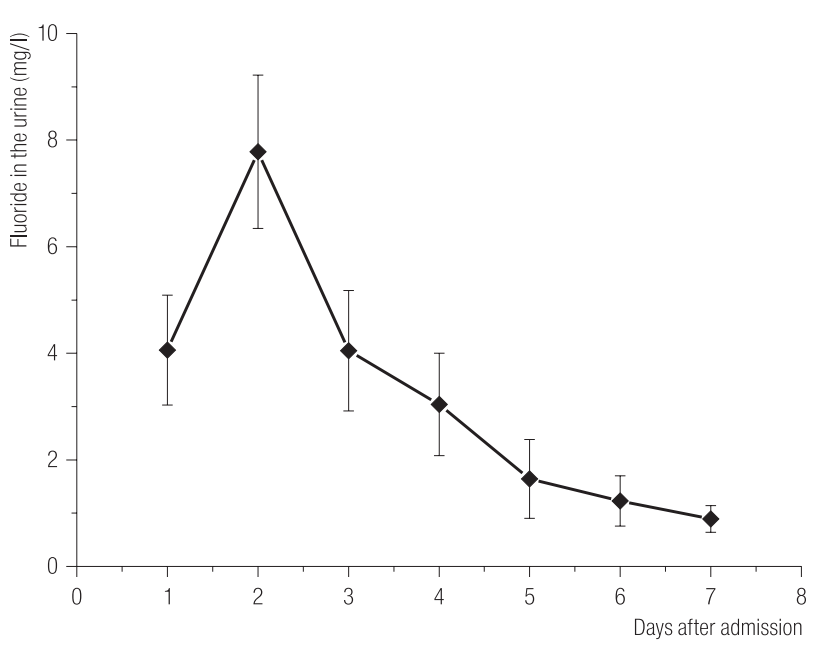

Fig. 2. The changes in morning urine fluorides for 14 inpatients

local compression for $15 \mathrm{~min}$ and another arterial puncture. No obvious hematoma formation, vasculitis or tissue necrosis were observed during the infusion. The monitoring of serum calcium ion indicated that no hypercalcemia occurred in any of the examined cases.

\section{DISCUSSION}

The Zhejiang Province, located in the southeast China, is an industrial area with a high incidence of chemical burns. In recent years, when the large chemical corporations have expanded their plants and increased production, lots of private enterprises and sole proprietorships have also been established and have enlarged their production scale. Subsequently, work-related chemical burns keep on the rise. According to incomplete statistics, thousands of patients suffer from chemical burns each year in the Zhejiang Province. HF has now become the most common substance to cause chemical injuries [3].

$\mathrm{HF}$ is a relatively weak acid, but it is strongly corrosive to biological tissues [8,9]. HF causes tissue injury by two different mechanisms. On the one hand, HF, as well as concentrated sulfuric acid and hydrochloric acid, can release $\mathrm{H}^{+}$in very high concentration, which causes immediate tissue destruction. On the other hand, fluorine ions can easily penetrate the skin and the lipid barrier, combine with calcium ions and magnesium ions in the hypodermal layer to form the insoluble salts, and specifically result in tissue liquefaction and necrosis [10]. The appearing time of clinical symptoms and signs after HF burn is strongly related to the concentration of HF to which the patient has been exposed and the duration of that exposure [11]. $\mathrm{HF}$, with the concentration greater than $50 \%$, can cause immediate pain and tissue injury, which could be found easily, and receive suitable treatment in time. The burns resulting from $\mathrm{HF}$ of lower concentration are too difficult to perceive at the early stage, which commonly leads to delayed treatment.

The critical procedure to treat HF burns is to block the progressive destruction caused by fluorine ions. The common neutralizing agents include calcium gluconate, magnesium sulfate and other substances. Calcium gluconate has been widely adopted as a better choice. The regional administration ways include topical wet compressing, local invasion injection, intravenous infusion, arterial infusion, etc. [12]. HF, with strong penetrating power, can penetrate the whole layer of skin in several minutes [13,14]. Compared with fluorine ions, calcium ions and magnesium ions have weaker tissue penetration power. Hence, their external use on wounds does not bring substantial curative effects.

Although the tissue penetration of calcium ions and magnesium ions could be enhanced by adding dimethyl sulfoxide [10] or using iontophoretic delivery [15], the practical effects remain controversial. Some auxiliary measures seem necessary. The local invasion injection of calcium gluconate is very suitable for the rich areas of skin soft tissues. The fingers and toes, with few hypodermal soft tissues and rich nerve endings, comprise dense tissues. The local injection can cause severe pain of the finger or toe, which could not be accepted by most patients.

Moreover, the local edema may occur in fingers and toes following HF burns. The local invasion injection 
Table 6. The results of laboratory examination after hydrofluoric burns

\begin{tabular}{lccccc}
\hline Indexes & $\begin{array}{c}\text { Patients } \\
(\mathrm{n})\end{array}$ & $\begin{array}{c}\text { range } \\
(\mathrm{mmol} / \mathrm{l})\end{array}$ & $\begin{array}{c}\mathrm{M} \pm \mathrm{SD} \\
(\mathrm{mmol} / \mathrm{l})\end{array}$ & $\begin{array}{c}\text { reference values } \\
(\mathrm{mmol} / \mathrm{l})\end{array}$ & $\begin{array}{c}\text { supplements } \\
(\mathrm{mmol} / \mathrm{l})\end{array}$ \\
\cline { 3 - 6 } & 118 & $1.88-2.80$ & $2.29 \pm 0.17$ & $2.00-2.80$ & 5 cases: $\mathrm{Ca}<2.00$ \\
Serum $\mathrm{Ca}$ & 118 & $0.54-0.99$ & $0.83 \pm 0.09$ & $0.66-1.20$ & 3 cases: $\mathrm{Mg}<0.66$ \\
Serum $\mathrm{Mg}$ & 118 & $0.14-25.8$ & $2.36 \pm 3.09$ & $0.00-1.70$ & 62 cases: $\mathrm{F}>1.70$ \\
\hline
\end{tabular}

$\mathrm{Ca}$ - Calcium ions; $\mathrm{Mg}$ - magnesium ions; $\mathrm{F}$ - fluoride.

$\mathrm{M}$ - mean; SD - standard deviation.

Table 7. General comparison of pain scores taking into account the patients' characteristics

\begin{tabular}{lccccc}
\hline \multicolumn{1}{c}{ Variable } & $\begin{array}{c}\text { Patients } \\
(\mathrm{n})\end{array}$ & $\begin{array}{c}\text { Pain score } \\
\text { (before infusion) }\end{array}$ & $\begin{array}{c}\text { Pain score } \\
\text { (4 h after infusion) }\end{array}$ & t value & F value \\
\hline $\begin{array}{l}\text { Gender } \\
\text { male }\end{array}$ & 107 & $6.43 \pm 1.52$ & $2.86 \pm 0.92$ & 20.78 & - \\
$\quad$ female & 11 & $6.57 \pm 1.08$ & $2.75 \pm 0.71$ & 9.81 & - \\
Age (years) & & & & & \\
14-30 & 37 & $6.59 \pm 1.14$ & $2.92 \pm 0.79$ & - & 491.21 \\
$31-45$ & 52 & $6.33 \pm 0.97$ & $2.83 \pm 0.95$ & - & 570.72 \\
$46-60$ & 26 & $6.54 \pm 1.23$ & $2.78 \pm 0.86$ & - & 354.67 \\
$>60$ & 3 & $5.84 \pm 1.45$ & $2.94 \pm 0.57$ & - & 185.78 \\
Patient type & & & & & \\
$\quad$ outpatients & 64 & $6.39 \pm 1.37$ & $2.84 \pm 0.98$ & 21.49 & - \\
$\quad$ inpatients & 54 & $6.88 \pm 1.24$ & $2.92 \pm 1.01$ & 9.26 & - \\
Patients receiving the first infusion & 118 & $6.45 \pm 1.53$ & $2.85 \pm 0.79$ & 22.71 & - \\
Patients receiving the second infusion & 11 & $7.68 \pm 1.18$ & $4.45 \pm 0.47$ & 8.43 & - \\
\hline
\end{tabular}

aggravating the swelling and pain, and even hampering the blood supply, is not suitable for the treatment of HF burns. The intravenous infusion as a systemic treatment, can be used to rectify the hypocalcemia and hypomagnesemia $[16,17]$. The Bier's block technique was first used by August Gustav Bier to perform anesthesia in the case of a limb surgery [18,19].

Graudins et al. [20] and Ryan et al. [21] adopted regional intravenous infusions of calcium gluconate using the Bier's block technique to treat the HF burns of limbs. Briefly, after blocking the circulation with the air pressure tourniquet near to the injured limb, the calcium gluconate solution was given by intravenous infusion. After 20-25 min, the tourniquet was released. Graudins et al. reported satisfactory results in 4 out of 7 examined cases, while the other 3 cases were further treated by the arterial infusion of calcium gluconate [20].

The arterial infusion of calcium gluconate, directly transporting the calcium ions to the burn regions, is suitable to treat not only the HF burns of the distal limbs, but the chemical burns of the head and face as well [22]. This method involving interrupted [23] or continuous [24] infusions, is easy to perform, and hardly needs any specific reagents or devices. Moreover, the treatment results are 
reliable, and do not lead to serious adverse effects. There are no standards regarding the dose and time of infusion. In this study, we selected the mixed solution of $10 \mathrm{ml}$ of $10 \%$ calcium gluconate and $20 \mathrm{ml}$ of $10 \%$ glucose as the neutralizer for HF burns, which was mainly based on basic knowledge and our clinical experience.

Firstly, according to the literature, HF has a strong ability to diffuse into human skin. It can reach the basal layer $2 \mathrm{~min}$ after exposure and completely penetrate human skin 5 min after contact [13]. Hence, calcium gluconate given in a short time $(15 \mathrm{~min}$ ) could be beneficial for rapid neutralization of fluoride ions, or calcium supplement, and further reduce the injury to the body. Secondly, comparing our results with those reported by other publications, the dose we used was effective and safe. The pain in most patients relieved after the first infusion, and there were no obvious adverse effects observed in our study. Thirdly, $10 \%$ calcium gluconate can be obtained conveniently and can be used after being quickly diluted with gluconate solution. This can be very important for emergency patients with HF burns.

Hatzifotis et al. [10] suggested that topical wet compressing of calcium gluconate should be selected for the HF burns of hands, whilst the regional intravenous and intra-arterial calcium infusion could be adopted as the advanced measures. The combined application of the above methods could also be used to produce a highly effective treatment [10]. This study indicated that topical wet compressing of calcium gluconate can be used in the pre-hospital care. For the outpatients and inpatients, the arterial infusion can be the preferential method.

When the skin gets burned with HF, the skin wounds progressively deepen. The wound depth is correlated not only with the concentration of HF to which the patient has been exposed and the duration of that exposure, but also with the treatment measures adopted at the early stage. The early arterial infusion of calcium gluconate can timely block the progressive injury, effectively relieve the pain, and block progressive wound deepening. A delay in the arterial infusion could result in an increase of the wound depth, entail more difficulties for advanced treatments, and affect the possible morbidity of scar formation or contracture. Many patients who were given the delayed infusion, had received the normal venous transfusion in other local clinics or hospitals, even in the large general hospitals, but had not been given any calcium or magnesium reagents to neutralize the fluorine ions in the local tissue and blood, which made the effects of the injury resulting from fluorine ions more persistent, and led to the situation in which the ideal opportunity for treatment was missed. Hence, it is essential to enhance the public awareness of HF burns, and improve the relevant treatment technologies.

The clinical therapeutic effect of HF burns treatment with the arterial infusion of calcium gluconate is undeniable. However, some situations could affect the therapeutic effect. Firstly, the pinhead of infusion may be punctured into the vein mistakenly, leading to the situation in which the calcium reagent has no access to the burn region. The arterial infusion of calcium reagents usually causes an obvious burning sensation in the limbs, which can be used to locate the puncture pinhead. Secondly, because of the dual arterial blood supply of the hands and feet, the infusion through the single artery usually does not cause the calcium reagent to be distributed effectively in the burn region. However, selecting the brachial artery as the punctured point, or compressing the other artery on the wrist or ankle when infused, can make the calcium distribute well. Thirdly, the velocity of infusion should be controlled appropriately. If the infusion progresses too fast, the calcium ions fail to bond the fluorine ions in the tissue to the maximum desirable extent. If the infusion is too slow, the tissue injury resulting from the effect of fluorine ions will deepen.

Finally, it is very important to handle correctly the bulla in the burn region. The formation of bulla can cause further 
pain by increasing the local tension. There is a large number of fluorine ions in the bulla water, which could cause progressive tissue injury. Hence, the removal of bulla and timely drainage are encouraged.

After HF burn of the skin, the fluorine ions infiltrate into the tissues and integrate with the calcium and magnesium, and further cause pain and progressive wound deepening. Moreover, the fluorine ions are also absorbed into the circulation system, and lead to hypocalcemia and hypomagnesemia. HF is a potentially dangerous substance and small-scaled burns resulting from it could lead to death. 3\% TBSA first-degree burns, resulting from $20 \%$ HF solution, can cause serious dysfunction of serum electrolyte and cardiac arrest [25].

Following a hydrofluoric acid burn, fluoride rapidly enters blood circulation through the skin and concentration peaks within an hour [26]. In this study, the largest burn area was not bigger than $3 \%$ of the total burn surface area (TBSA), but the level of urine fluorides was at least 10 times higher than the normal level. This indicated that small-scaled HF burns also cause fluorosis. In addition to the treatment of HF burns using the arterial infusion, the systemic effects caused by HF burns should also be focused on if necessary.

In this study, the arterial infusion of calcium gluconate to treat hydrofluoric acid burns of the distal human limbs demonstrated satisfactory results. However, the dosage of calcium gluconate was not individually adjusted according to the patients' weight, wound size and depth, and the frequency of infusions did not exceed 2 times. Hence, the best treatment effect could not have been obtained, or confirmed. Whether the repeated infusions or continuous small-dosage maintenance following the first infusion could result in a better effect is worthy to become the subject of further studies. In addition, the effects of wet compressing of calcium gluconate could be easily affected by the weak penetration of calcium ions and topical dryness due to the evaporation of water. The arterial infusion of calcium gluconate, in combination with the topical use of hydrating gels (containing dimethyl sulfoxide, calcium, magnesium ions, etc.) could bring better results of medical intervention.

\section{CONCLUSIONS}

The arterial infusion of calcium gluconate, effectively relieving the pain, blocking wound progressive deepening, and leading to no adverse effects, could be the preferential method to treat hydrofluoric acid burns of the distal human limbs.

\section{REFERENCES}

1. Martin HC, Muller MJ. Hydrofluoric acid burns from a household rust remover. Med J Aust. 2002;176:296.

2. Perry HE. Pediatric poisonings from household products: hydrofluoric acid and methacrylic acid. Curr Opin Pediatr. 2001; 13:157-61, http://dx.doi.org/10.1097/00008480-20010400000013.

3. Zhang YH, Han CM, Chen GX, Ye CJ, Jiang RM, Liu LP, et al. Factors associated with chemical burns in Zhejiang province, China: An epidemiological study. BMC Public Health. 2011;11:746, http://dx.doi.org/10.1186/1471-245811-746.

4. Ohata U, Hara H, Suzuki H. 7 cases of hydrofluoric acid burn in which calcium gluconate was effective for relief of severe pain. Contact Dermatitis. 2005;52:133-7, http:/dx.doi. org/10.1111/j.0105-1873.2005.00521.x.

5. Thomas D, Jaeger U, Sagoschen I, Lamberti C, Wilhelm K. Intra-arterial calcium gluconate treatment after hydrofluoric acid burn of the hand. Cardiovasc Intervent Radiol. 2009;32:155-8, http://dx.doi.org/10.1007/s00270-0089361-1.

6. Stuke LE, Arnoldo BD, Hunt JL, Purdue GF. Hydrofluoric acid burns: A 15-year experience. J Burn Care Res. 2008;29: 893-6, http://dx.doi.org/10.1097/BCR.0b013e31818b9de6. 
7. Bijur PE, Silver W, Gallagher EJ. Reliability of the visual analog scale for measurement of acute pain. Acad Emerg Med. 2001;8:1153-7, http://dx.doi.org/10.1111/ j.1553-2712.2001.tb01132.x.

8. Summers A. Treating burns caused by hydrofluoric acid. Emerg Nurse. 2011;19:12-5; quiz 17.

9. Capitani EM, Hirano ES, Zuim Ide S, Bertanha L, Vieira RJ, Madureira PR, et al. Finger burns caused by concentrated hydrofluoric acid, treated with intra-arterial calcium gluconate infusion: case report. Sao Paulo Med J. 2009;127: 379-81.

10. Hatzifotis M, Williams A, Muller M, Pegg S. Hydrofluoric acid burns. Burns. 2004;30:156-9, http://dx.doi.org/10.1016/ j.burns.2003.09.031.

11. Kirkpatrick JJ, Enion DS, Burd DA. Hydrofluoric acid burns: A review. Burns. 1995;21:483-93, http://dx.doi. org/10.1016/0305-4179(95)93254-H.

12. Schiettecatte D, Mullie G, Depoorter M. Treatment of hydrofluoric acid burns. Acta Chir Belg. 2003;103:375-8.

13. Burgher F, Mathieu L, Lati E, Gasser P, Peno-Mazzarino L, Blomet J, et al. Experimental 70\% hydrofluoric acid burns: histological observations in an established human skin explants ex vivo model. Cutan Ocul Toxicol. 2011;30:100-7, http://dx.doi.org/10.3109/15569527.2010.533316.

14. Ohtani M, Nishida N, Chiba T. Pathological demonstration of rapid involvement into the subcutaneous tissue in a case of fatal hydrofluoric acid burns. Forensic Sci Int. 2007;167: 49-52, http://dx.doi.org/10.1016/j.forsciint.2005.12.008.

15. Yamashita M, Suzuki M, Hirai H, Kajigaya H. Iontophoretic delivery of calcium for experimental hydrofluoric acid burns. Crit Care Med. 2001;29:1575-8, http://dx.doi. org/10.1097/00003246-200108000-00013.

16. Sanz-Gallén P, Nogué S, Munné P, Faraldo A. Hypocalcaemia and hypomagnesaemia due to hydrofluoric acid. Occup Med.2001;51:294-5, http://dx.doi.org/10.1093/occmed/51.4.294.

17. Dalamaga M, Karmaniolas K, Nikolaidou A, Papadavid E. Hypocalcemia, hypomagnesemia, and hypokalemia following hydrofluoric acid chemical injury. J Burn
Care Res. 2008;29:541-3, http://dx.doi.org/10.1097/BCR. 0b013e3181711152.

18. van Zundert A, Helmstadter A, Goerig M, Mortier E. Centennial of intravenous regional anesthesia. Bier's Block (1908-2008). Reg Anesth Pain Med. 2008;33:483-9, http:// dx.doi.org/10.1016/j.rapm.2008.04.011.

19. Van Zundert A, Goerig M. August Bier 1861-1949. A tribute to a great surgeon who contributed much to the development of modern anesthesia on the 50th anniversary of his death. Reg Anesth Pain Med. 2000;25:26-33, http://dx.doi. org/S1098-7339(00)80007-3.

20. Graudins A, Burns MJ, Aaron CK. Regional intravenous infusion of calcium gluconate for hydrofluoric acid burns of the upper extremity. Ann Emerg Med. 1997;30:604-7, http:// dx.doi.org/S0196-0644(97)70076-3.

21. Ryan J, McCarthy G. Regional intravenous calcium - An effective method of treating hydrofluoric acid burns to limb peripheries. J Accid Emerg Med. 1997;14:401-4, http:// dx.doi.org/10.1136/emj.14.6.401.

22. Nguyen LT, Mohr WJ, 3rd, Ahrenholz DH, Solem LD. Treatment of hydrofluoric acid burn to the face by carotid artery infusion of calcium gluconate. J Burn Care Rehabil. 2004;25:421-4, http://dx.doi.org/10.1097/01.BCR. 0000138288.15403.BA.

23. Siegel DC, Heard JM. Intra-arterial calcium infusion for hydrofluoric acid burns. Aviat Space Environ Med. 1992;63:206-11.

24. Lin TM, Tsai CC, Lin SD, Lai CS. Continuous intra-arterial infusion therapy in hydrofluoric acid burns. J Occup Environ Med. 2000;42:892-7, http://dx.doi.org/10.1097/00043764200009000-00008.

25. Wu ML, Deng JF, Fan JS. Survival after hypocalcemia, hypomagnesemia, hypokalemia and cardiac arrest following mild hydrofluoric acid burn. Clin Toxicol (Phila). 2010;48:953-5, http://dx.doi.org/10.3109/15563650.2010.533676.

26. Yang SJ, Zhang YH, Liu LP. Comparison of various methods of early management of hydrofluoric acid burn in rabbits. Chinese J Burns. 2005;21:40-2.

This work is available in Open Access model and licensed under a Creative Commons Attribution-NonCommercial 3.0 Poland License - http://creativecommons.org/ licenses/by-nc/3.0/pl/deed.en. 